\title{
FutureJournal
}

\section{Teoria dos Jogos: Dinâmica de Ensino dos Aspectos do Processo de Decisão}

\author{
Helio Oliveira Santos \\ Graduado no Curso de Ciências Econômicas pela UFC - Universidade Federal do Ceará, Brasil \\ heliosantoseconomia@gmail.com \\ Eveline Barbosa Silva Carvalho \\ Professora da UFC - Universidade Federal do Ceará, Brasil \\ eveline@ufc.br
}

\section{RESUMO}

$\mathrm{Na}$ presente pesquisa, objetivou-se avaliar a aplicabilidade do conhecimento em teoria dos jogos em simulações de disputas empresariais e verificar os efeitos das emoções sobre o processo de tomada de decisão. Foram elaboradas simulações de competição a partir do conteúdo de teoria dos jogos e aplicadas a turmas de diversos tamanhos. Durante as simulações, os participantes travam uma disputa fictícia com um colega de sala, os resultados individuais das decisões dependem não só das próprias ações mas também das decisões do adversário. O ambiente competitivo foi criado por meio de premiações e, dessa forma, os alunos foram impelidos a formular as próprias táticas para obter melhor resultado e alcançar o prêmio. 0 aprendizado ocorreu inicialmente pelo meio clássico de tentativa e erro. Depois que os resultados das simulações foram analisados em sala de aula, os alunos tiveram acesso à teoria e às técnicas convencionais já desenvolvidas nos meios acadêmicos. O modelo logit de escolha qualitativa foi utilizado para analisar os resultados em diferentes rodadas e turmas. Os resultados dos experimentos permitem corroborar a teoria, que em geral se mostrou robusta em prever o comportamento dos jogadores e as estratégias adotadas diante das situações apresentadas.

PALAVRAS-ChAVE: Dinâmica para ensino. Teoria dos jogos. Estratégias de decisão. 


\section{FutureJournal}

\section{Game Theory: Teaching Dynamics of Decision Process Aspects}

\section{ABSTRACT}

This study aimes to evaluate the applicability of knowledge of game theory in business simulations and verify the effects of emotions on the decision-making process. Competition simulations were drawn from game theory content and applied to groups of various sizes. During the simulation, participants perform a fictitious dispute with a classmate where the individual results of decisions depends not only on one's actions but also on the opponent's decisions. The competitive environment has been created through awards. Thus the students were urged to develop their own tactics to achieve better results and win the prize. Learning initially occurred through classic trial and error. The simulations results were analyzed in the classroom and after that students had access to the theory and conventional techniques already developed in academic circles. A logit model of qualitative choice was used to analyze the results in different rounds and classes. The experiments results allow to corroborate the theory that in general has proved robust in predicting the behavior of players and strategies in the face the situations presented.

KEY-WORDS: Dynamic to teaching. Game theory. Decision strategies. 


\section{INTRODUÇÃO}

A tomada de decisão tem intrigado a humanidade desde tempos remotos. Surge sempre que os indivíduos são impelidos a agir de alguma forma para atender a suas necessidades em meio à escassez de recursos e à presença de outros indivíduos que podem influenciar o resultado de suas ações.

O desenvolvimento enfrentado pela sociedade e o desejo contínuo do homem de alcançar mais elevados patamares de bem-estar tornaram a arte de decidir um tema recorrente nos círculos intelectuais ao redor do mundo em diferentes épocas. Autores como Sun Tzu, Nicolau Maquiavel e Miyamoto Musashi escreveram sobre como tomar decisões eficientes em diversas áreas na tentativa de criar manuais de auxílio à tomada de decisão. Mas a sistematização da tomada de decisão só se tornou palpável em meados dos anos 1930, quando surgiram os trabalhos de Von Neumann e os primeiros estudos sobre o proeminente ramo da matemática chamado de Teoria dos Jogos, que revolucionou a arte da tomada de decisão.

A Teoria dos Jogos é um compilado de técnicas matemáticas, utilizadas para auxiliar a análise de fenômenos de caráter decisório. Esse tipo de estudo visa não ofertar uma resposta rígida para todos os problemas, e sim oferecer ferramentas de análise a serem utilizadas para identificar detalhes essenciais à boa tomada de decisão, como as possíveis escolhas dos agentes e suas respectivas consequências.

Desde o seu surgimento, a Teoria dos Jogos tem sido vastamente aplicada nas mais diversas áreas da ciência como política, estratégia militar, esportes, biologia, filosofia, computação, economia e administração. Os grandes arquitetos da teoria frequentemente utilizam alegorias para identificar e classificar tipos de jogos que apresentam diferentes características, como o conhecido dilema do prisioneiro, a guerra dos sexos ou a caça ao cervo, e seu estudo não raramente requer grande capacidade de abstração do estudante, compelindo-o a arquitetar mentalmente os diversos ambientes decisórios.

Apesar de sua importância, não é difícil observar certo desinteresse entre os alunos causado pela dificuldade de reconhecer a aplicabilidade do 
conteúdo exposto em sala de aula, ou mesmo pela dificuldade em visualizar situações definidas em teorias apresentadas. Além disso, muitas vezes são representados modelos simplificados, em vez de interações complexas, como disputas empresariais, o que acarreta o não aprendizado e, consequentemente, a não utilização posterior da teoria pelos profissionais no mercado. Partindo do pressuposto de que a experiência tem grande valor no processo de aprendizado e que o uso de simulações pode aumentar o interesse dos alunos pelos estudos de jogos, melhorando a captação do ensino, no presente trabalho, avaliou-se a aplicabilidade do conhecimento em teoria dos jogos confrontando o desempenho dos alunos em simulações de disputas empresariais elaboradas a partir do conteúdo de teoria dos jogos com os resultados previstos pela teoria.

Considerando que um dos alvos mais frequentes das críticas à teoria é a hipótese da racionalidade, que exclui influência das emoções no processo de decisão, pretendeu-se, ainda, verificar os efeitos das emoções sobre o processo de tomada de decisão e se seriam suficientes para anular a hipótese da racionalidade.

Além desta introdução, na pesquisa aborda-se o referencial teórico incluindo a origem da teoria dos jogos, o processo de tomada de decisão e o papel das emoções no processo decisório. Em seguida, é apresentada a metodologia utilizada por meio dos jogos utilizados nas simulações, o processo de premiação, a execução do experimento e o modelo logit utilizado para análise dos resultados das simulações. Em seguida são apresentados os resultados e as discussões e, por fim, as conclusões.

\section{REFERENCIAL TEÓRICO}

\subsection{ORIGEM DA TEORIA DOS JOGOS}

Segundo Fiani (2006), os primeiros trabalhos sobre teoria dos jogos estão relacionados aos estudos do matemático húngaro John Von Neumann (1903-1957). Em parceria com o economista alemão Oskar Morgenstern (1902-1977), Neumann publicou em 1944 o livro The theory of games and economic behavior, que propunha uma solução matemática para um 
problema conhecido como jogo de soma zero, situação de competição em que o ganho de um dos jogadores representa uma perda de igual valor aos outros.

Ao analisar jogos de soma zero em etapas sucessivas, esses autores conseguiram identificar situações em que há cooperação entre os jogadores. A obra foi uma tentativa de sistematizar o comportamento estratégico das pessoas em qualquer ocasião; estudo que passou a ser conhecido como teoria dos jogos.

Embora a obra tenha sido de fundamental importância, o uso de jogos de soma zero apresentava limitações em decisões que envolviam um grande número de interações entre indivíduos. Essas limitações seriam superadas no início dos anos 1950 por John Nash (1928-2015).

Em seu artigo de 1951, "Non-cooperative games", Nash definiu uma ferramenta teórica que permitia analisar uma variedade maior de modelos de interação estratégica por meio da análise de jogos em que os jogadores tomam decisões simultâneas sem qualquer tipo de informação sobre o adversário. Nash propôs um estado de equilíbrio, conhecido como equilíbrio de Nash, no qual os participantes do jogo a fim de obter melhor resultado não mudam de escolha devido à presunção de que as atitudes dos adversários, também à procura de maior ganho, podem Ihes causar perdas. A partir de então, houve um grande florescimento da teoria dos jogos em diversas áreas da ciência.

Apesar do enorme avanço, a teoria ainda apresentava limitações quando se tratava de jogos em que alguns jogadores dispunham de informação privilegiada em relação aos demais. Em tais situações, em que há assimetria de informações, foi fundamental a contribuição do economista húngaro John C. Harsanyi (1920-2000) para o advento da teoria, estendendo o modelo de equilíbrio de Nash para o que viria a ser conhecido como modelo de informação incompleta.

A noção de equilíbrio foi ainda refinada pelo matemático e economista alemão Reinhard Selten (1930-2016), em artigo publicado em 1965. A nova versão, conhecida como equilíbrio perfeito em subjogos, tratava da melhor escolha considerando todos os possíveis desdobramentos em jogos que continham diversas rodadas. O estudo possibilitou avaliar a 
veracidade de acordos e ameaças em jogos sequenciais em que há possibilidade de negociação entre os jogadores.

Essas foram as mais relevantes contribuições para o conhecimento da teoria dos jogos, no entanto as pesquisas continuam até os dias de hoje, alcançando diversos ramos da ciência.

\subsection{PROCESSO DE TOMADA DE DECISÃO}

A tomada de decisão está continuamente presente na vida humana. Segundo Rocha e Freitas (2011), os seres humanos deparam-se com uma situação de escolha sempre que são impelidos a satisfazer necessidades a fim de alcançar um objetivo.

Observando-se o comportamento de um agente isolado, é possível perceber que a escolha da ação adequada pode ser simples, quando há um reduzido número de opções de ações, e se torna mais complexa à medida que aumenta o número de opções de ações alternativas para satisfação da necessidade. A decisão depende do conhecimento prévio acerca dos benefícios e riscos esperados e do custo da efetivação de cada uma das possíveis ações.

Feita a seleção da maneira aparentemente mais eficaz de agir, é preciso monitorar sua execução e os desdobramentos resultantes da decisão, ajustando sempre que necessário, na tentativa de maximizar os benefícios e minimizar os custos e riscos. Após o término da ação, há uma avaliação dos resultados obtidos, comparando-se com benefícios, riscos e custos envolvidos.

O aprendizado adquirido a partir do sucesso ou não da ação em suprir uma necessidade pode surgir como novo conhecimento ou como atualização de conhecimentos adquiridos em atuações anteriores e deve ser utilizado em futuras decisões. Esse novo conhecimento vem da avaliação de todos os custos e riscos envolvidos na execução da ação e dos benefícios obtidos.

De acordo com Rocha e Freitas (2011), as ações, depois de avaliadas, podem ser classificadas em dois grupos: (1) conjunto de ações satisfatórias, em que estão presentes as atuações que geraram melhor 
relação entre benefício, custo e risco; e (2) conjunto de ações não satisfatórias, em que estão as ações de pior resultado. Esse conhecimento deve ser utilizado quando surgir uma decisão similar à feita anteriormente.

\subsection{O PAPEL DAS EMOÇÕES NO PROCESSO DECISÓRIO}

A dificuldade de mensurar as reações emocionais humanas conduziu a ciência a consagrar a hipótese do agente racional como melhor explicação plausível sobre o comportamento humano, o que acarretou uma dicotomia entre $\mathrm{o}$ pensamento racional e o emocional, que são considerados antagônicos como as faces de uma moeda, já que o emocional é considerado irracional.

Algumas vezes simplesmente não agimos de forma racional. Isso pode acontecer, em primeiro lugar, porque nossas emoções impedem que avaliemos as consequências de um ato em relação aos nossos objetivos. Isso resulta do fato de que algumas vezes padrões inconscientes de comportamento se impõem sobre a nossa capacidade de escolha deliberada, resultando naquilo que, em linguagem corrente, definimos como agir "sem pensar". (Fiani, 2006, p. 10)

Esse pressuposto apresenta debilidades quanto à previsão de efeitos resultantes de reações emocionais. Contudo, problemas podem ser amenizados a partir de avanços experimentados pela neurociência no mapeamento e monitoramento de reações cerebrais, uma vez que a maior precisão permite a medição das reações emocionais dos seres humanos em diversas situações, criando novos campos de estudos, entre os quais está a neuroeconomia.

A neuroeconomia é o estudo da função cerebral como meio de examinar e complementar os modelos teóricos sobre o comportamento econômico. O novo ramo possibilitou a introdução das emoções na análise do processo de decisão, o que a tornou um tanto mais complexa, porém mais abrangente, já que permite examinar soluções que são tomadas não apenas maximizando os ganhos do ponto de vista da teoria da escolha racional.

A nova linha de pensamento afirma que a seleção da ação a ser executada, bem como a avaliação de satisfação feita após a sua implementação, depende não só da relação entre o benefício e o risco 
esperado, como também do conflito gerado pelas percepções pessoais de risco, benefício e custo do agente tomador da decisão.

As sensações de facilidade ou dificuldade variam de uma pessoa para outra devido às diferenças psicológicas entre elas. Pessoas propensas ao estresse enfrentam maior dificuldade em tomar decisões, diferentemente de outras mais tolerantes, que conseguem manter-se calmas mesmo sob pressão. Essa percepção só é possível graças às reações emocionais. A dificuldade é percebida através dos sentimentos de aflição, angústia, frustração, enquanto a facilidade é acompanhada por um sentimento de satisfação ou contentamento, podendo chegar à euforia.

O conflito gerado por cada execução ou adequação pode ser medido a partir da relação (risco calculado) / (benefício esperado) que tende a ser maior à medida que a razão risco/benefício se aproxima de 1 (Rocha \& Freitas, 2011).

O conflito enfrentado reflete-se no esforço cerebral despendido para realização dos cálculos envolvidos no procedimento. Quando o benefício esperado é muito superior ao risco calculado, ou o contrário, o conflito é pequeno e a decisão de executar ou não a ação se torna fácil, exigindo pouco esforço intelectual. Entretanto, quando a razão risco/benefício se aproxima de 1 , o conflito aumenta e a decisão se torna gradativamente mais difícil, exigindo um esforço mental maior.

A sensação de dificuldade de decisão é função do conflito e da tolerância ao estresse. As pessoas com maior dificuldade podem tentar evitar o problema retardando ao máximo a tomada de decisão ou, em virtude da ansiedade, anteciparem o processo a fim de se sentirem livres o mais rápido possível do incômodo causada pelo conflito.

\section{METODOLOGIA}

Diferentemente do método teórico direto muito comum nas instituições de ensino de todo o mundo, em que o aluno assume uma posição passiva de assimilar o conhecimento exposto em sala, memorizar e futuramente talvez aplicar, o processo utilizado faz o estudante vivenciar o problema antes de tudo. 
É apresentado em sala um problema a ser resolvido sobre o assunto de estudo por meio de simulações que envolvem o aluno na atmosfera da teoria. Esse processo dá às pessoas a oportunidade de descobrir as motivações que originaram o conhecimento, vivenciando os problemas do estudo antes mesmo de aprender sobre o tema.

\subsection{JOGOS UTILIZADOS NA SIMULAÇÃO}

Em uma região há apenas duas empresas: empresa A e empresa B. As duas têm atuação em toda a região e estão considerando agir como cartel para determinar preços mais altos.

O administrador de cada empresa define no início do período o preço do produto que deve permanecer inalterado por pelo menos um período. Se as duas empresas oferecerem preços iguais e mais altos, as duas terão um lucro maior ( 5 unidades monetárias cada) e dividirão o mercado. No entanto, se apenas uma delas aumentar o preço e a outra não, a empresa com o menor preço vai ganhar todo o mercado e terá um lucro ainda maior do que se participasse do cartel (9 unidades monetárias). Da mesma forma, a empresa que elevar sozinha o preço terá um lucro menor que o lucro do cartel ( 1 unidade monetária). Se as duas empresas não elevarem seus preços, elas continuarão dividindo o mercado, mas com um lucro menor do que o lucro do cartel ( 3 unidades monetárias cada). Colocada tal situação, é feito o seguinte questionamento aos alunos: sendo você o gerente de uma das empresas e sabendo que ambas só funcionarão durante um período, o que você sugere? Aumentar ou manter o preço no período?

Esse jogo pode ser descrito como simultâneo, já que ambos os jogadores tomam decisão ao mesmo tempo; de informação imperfeita, pois não há histórico de decisões anteriores; e completo, pois ambos sabem quais as estratégias possíveis dos concorrentes.

A partir da matriz de payoffs descrita na Tabela 1 e supondo-se que todos os jogadores são maximizadores de ganho (hipótese da racionalidade), é possível perceber que o jogo apresenta um equilíbrio de Nash (Não coopera, Não coopera), que também é um equilíbrio de 
estratégia dominante, uma vez que não cooperar deve ser sempre a estratégia escolhida por um jogador, independentemente da escolha do outro. Ou, seja, nesse caso, a decisão mais racional é não cooperar com o cartel praticando preço baixo.

Tabela 1: Matriz de payoffs do jogo utilizado na dinâmica

\begin{tabular}{l|c|c|c}
\hline & \multicolumn{3}{|c}{ JOGADOR 2 } \\
\hline \multirow{3}{*}{ JOGADOR 1 } & & Cooperar & Não cooperar \\
\cline { 2 - 4 } & Cooperar & $(5 ; 5)$ & $(1 ; 9)$ \\
\cline { 2 - 4 } & Não cooperar & $(9 ; 1)$ & $(3 ; 3)$ \\
\hline
\end{tabular}

Fonte: Elaborada pelos autores

Em uma conjuntura em que o mesmo jogo venha a repetir-se sem prazo para terminar e em que haja oportunidades de negociação, a teoria atesta que cada jogador vai sentir-se atraído a cooperar com o cartel para obter lucros altos durante diversos períodos. O fato de sempre contar com rodadas futuras dá segurança aos jogadores de propor a aliança uns aos outros, pois, caso o oponente não cumpra o acordo, pode ser punido nas próximas rodadas pelo emprego da estratégia tit-for-tat, ou seja, um jogador coopera se o outro cooperar e não coopera se o outro não cooperar. Nesse contexto, a escolha que proporciona maior prêmio é cooperar com o cartel ofertando preços altos.

De outro modo, caso sejam mantidas as condições de informação completa e perfeita, e o jogo seja repetido por um número finito de vezes conhecido pelos jogadores, ou seja, tenha prazo para acabar, na última repetição, nenhum dos jogadores vai ter garantias concretas de que o outro vai continuar cooperando. Fazendo-se uma análise regressiva, na derradeira repetição, supondo que os jogadores ajam racionalmente e levem em conta somente os prêmios do jogo, todos vão optar por não cooperar, pois não haverá rodadas seguintes para possíveis retaliações contra quebras de acordos. Mas ambos os jogadores, sabendo que seus oponentes têm essa informação, vão tentar agir antecipadamente não cooperando na penúltima rodada. Esse raciocínio segue até que chegue a primeira decisão do jogo finitamente repetitivo. Assim, a melhor decisão racional, considerando-se apenas os ganhos, é não cooperar desde o início do jogo finitamente repetitivo. No entanto, a adoção desse tipo de estratégia é ineficiente, pois 
produz resultados muito aquém dos possíveis ganhos resultantes da cooperação.

A dificuldade de alcançar o ponto mais eficiente é que a manutenção de um comportamento cooperativo aqui só é possível se, durante o jogo, ambos tenham criado uma reputação que dê credibilidade aos compromissos assumidos.

\subsubsection{Premiação}

Para gerar o ambiente competitivo, foram concedidos pequenos prêmios a fim de sair do plano fantasioso para o mais próximo possível da realidade.

Os participantes que alcançarem ganhos extraordinários são premiados da seguinte forma: quem dominar todo o mercado $e$, consequentemente, obtiver lucro de monopólio ganha um grande bombom de chocolate; o participante que dividir o mercado a preço alto, obtém lucro de cartel (aproximadamente a metade do lucro de monopólio) e recebe um bombom de chocolate de tamanho aproximado de meio bombom grande; quem dividir o mercado a preços baixos, não obterá nenhum lucro extraordinário, logo não recebe nada.

\subsection{EXECUÇÃO DO EXPERIMENTO}

O processo é uma adaptação de uma técnica chamada Ciclo de Aprendizagem Vivencial (CAV) - bastante utilizada na andragogia, do grego andros, adulto, e gogos, educar -, que consiste em um conjunto de técnicas educacionais para ensino de adultos.

A técnica é originalmente composta de cinco estágios: vivência, relato, processamento, generalização e aplicação. No entanto, como o experimento será aplicado em estudantes profissionais, foi adotado um formato mais dinâmico, dividindo-o em apenas três partes: recepção dos jogadores, simulação e análise da dinâmica, que analisa os padrões comportamentais resultantes. 


\subsubsection{Recepção dos jogadores e aplicação da simulação}

Durante os primeiros 20 minutos, os alunos são recebidos e alertados de que, ao começar o experimento, não haverá interrupções ou inclusão de novos jogadores. Logo depois, é entregue a cada aluno (já em seus devidos lugares) um envelope contendo três documentos. O primeiro é uma cópia do jogo como as apresentadas nos anexos A, B e C. O segundo contém a identificação dos alunos no jogo e onde atuarão, de modo que um aluno que receba um documento em que está escrito Empresa A - Região 01, tomará decisões pela empresa $A$ e sabe também que essa empresa atua na região 01 em que há outra empresa (Empresa B - Região 01) atuando, já que é revelado previamente que o jogo ocorre em situação de duopólio. Desse modo, o nome da região (cidade ou país, dependendo da dinâmica) na verdade identifica a dupla de jogadores adversários. O terceiro e último documento é um formulário de decisão, uma espécie de bilhete em que o jogador deve escrever seu primeiro nome, sua identificação no jogo e marcar, entre as opções, a ação que pretende implementar (atuar com preços altos ou praticar preços baixos).

A simulação tem ao todo três etapas. 0 jogo simultâneo corresponde à primeira fase da simulação e é composto de apenas uma rodada. Tem início logo que os alunos consultam os documentos ao mesmo tempo e tomam posse das informações sobre suas identidades e sobre o jogo. Os alunos devem decidir sem saber quem é seu adversário e sem nenhuma perspectiva de jogar novamente, fatos que caracterizam um jogo simultâneo de informação completa (já que ambos conhecem suas recompensas e as do concorrente) e imperfeita (já que não há histórico de ações anteriores para ser consultado durante a tomada de decisão). É estipulado que o tempo para a decisão seja de dez minutos, podendo ser prolongado a fim de que todos entreguem seus formulários de decisão. 0 término dessa fase ocorre quando todos os participantes entregam seus respectivos formulários.

Com a ajuda de um computador e um projetor, as decisões de todos os participantes são computadas e simultaneamente é revelada a todos a identidade de seus concorrentes e suas decisões, premiando cada jogador de acordo com os resultados obtidos por meio de suas escolhas. 
Ao terminar a rodada, os alunos são convidados a jogar novamente por incontáveis rodadas até que termine o horário da aula. Assim, inicia-se o jogo repetido infinitas vezes, que corresponde à segunda etapa da simulação. Nessa fase, os participantes conhecem as estratégias dos oponentes (jogo de informação completa), o histórico de decisão do adversário (jogo de informação perfeita) e sabem que jogarão novamente diversas vezes (fato que deixa a impressão de que o jogo se repete infinitamente). Outro fato que muda é a possibilidade de livre negociação. Os participantes podem negociar livremente, desde que, ao preencher seus formulários de decisão, estejam sozinhos, para que não sofram coação de outros alunos.

A coleta de todas as folhas de decisão marca o fim da rodada e mais uma vez são reveladas a todos as escolhas feitas por cada participante, sendo cada um premiado novamente de acordo com os resultados. Feita a conferência dos ganhos, mais uma roda se inicia e esse ciclo se repete indefinidas vezes até que o tempo da primeira fase da simulação, somado ao tempo da segunda, seja equivalente a 55 minutos, conforme a Tabela 2.

Com a repetição do jogo, participantes têm a oportunidade de analisar o ocorrido em rodadas anteriores e mudar os próprios padrões de decisão a partir da avaliação dos resultados individuais e coletivos das interações.

Tabela 2: Cronograma de execução da dinâmica

\begin{tabular}{|c|c|c|}
\hline \multicolumn{2}{|l|}{ FASES } & TEMPO DE DURAÇÃO \\
\hline \multicolumn{2}{|l|}{ Recepção de alunos } & $00: 20$ \\
\hline \multirow[t]{3}{*}{ Vivência } & Jogo simultâneo & $00: 55$ \\
\hline & Jogo retido infinito & \\
\hline & Jogo repetido finito & $00: 05$ \\
\hline \multicolumn{2}{|l|}{ Relato } & \\
\hline \multicolumn{2}{|l|}{ Processamento } & $00: 30$ \\
\hline \multicolumn{2}{|l|}{ Generalização } & \\
\hline \multicolumn{2}{|l|}{ Aplicação } & \\
\hline \multicolumn{2}{|l|}{ Total } & 1 hora e 50 minutos \\
\hline
\end{tabular}

Fonte: Elaborada pelos autores

Aos exatos 55 minutos de decorrência da simulação, tem início a terceira e última fase, composta apenas de uma rodada de duração máxima de cinco minutos. Os jogadores são avisados de que só jogarão uma última 
vez, o que torna o jogo finito novamente, mas continuam com os mesmos adversários e com as mesmas opções anteriores o que garante que o jogo continue sendo de informação perfeita e completa. Como nas rodadas anteriores, os resultados são computados e cada um é recompensado de acordo com o resultado alcançado.

\subsubsection{Análise da simulação}

Encerrado o jogo, há a fase do relato. Nesse período os alunos têm espaço para falar sobre dificuldades enfrentadas e emoções vivenciadas. Esse espaço é essencial para dissipar o clima tenso que normalmente se instala quando o jogo se torna muito competitivo.

Os jogos propiciam um clima de alta tensão e, mesmo sendo atividades simuladas, implicam alto envolvimento das pessoas na tentativa de resolver problemas ou desafios lançados. Ao participar intensamente no processo, as pessoas não conseguem esconder suas dificuldades e habilidades, o que afeta diretamente o emocional de cada um. (Grâmigna, 1993, p. 23)

Logo em seguida, as discussões são direcionadas para a análise do jogo, dando início ao que seria, no Ciclo da Aprendizagem Vivencial, a fase de processamento, na qual os alunos avaliam a eficácia de suas escolhas relacionando-as com os resultados obtidos. Durante essa avaliação, cada uma das três fases da vivência merece a devida atenção já que todas possuem estratégias ótimas divergentes.

Após o processamento, são apresentados aos alunos os modelos teóricos já desenvolvidos nos meios acadêmicos que descrevem as situações vividas na dinâmica. Nesse estágio, conhecido como generalização, os estudantes saem de vez do clima da simulação para o ambiente teórico em que se deparam com as possíveis explicações sobre os comportamentos adotados pelos jogadores. O facilitador apresenta todo esse conteúdo através de vídeo ou oratória, mas com o cuidado de sempre estimular os estudantes a identificarem que situação cada teoria descreve.

O CAV, na adaptação proposta, é concluído com uma discussão sobre a aplicabilidade da teoria dos jogos na vida real. Nessa fase, o debate gira em torno de exemplos reais de tomadas de decisão e os alunos são 
estimulados a pensar sobre possíveis aplicações e se os modelos replicam ou não a realidade de maneira aceitável.

\subsection{MODELO LOGIT PARA ANÁLISE DOS RESULTADOS}

Durante os experimentos, os resultados são computados, expostos aos alunos e analisados visualmente fomentando posterior debate sobre as melhores práticas em determinada fase do jogo. Nesse trabalho, para descrever se as reais motivações das escolhas feitas pelos participantes convergem com as apresentadas em teoria, a partir de dados gerados nos experimentos, foi utilizado o modelo de escolha qualitativa conhecido como Logit.

Modelos de escolha qualitativa supõem que indivíduos e firmas se deparam com escolha entre duas ou mais alternativas e que sua decisão depende de um conjunto de características observáveis. Esses modelos também são conhecidos como modelos de probabilidade, pois a variável de resposta $Y$ reflete a probabilidade de o indivíduo escolher uma alternativa em lugar de outra, dado um conjunto de atributos observáveis.

$$
E\left(Y_{i} / X_{i}\right)=\beta_{0}+\beta_{1} X_{i}+u_{i}
$$

O Logit é um modelo utilizado para análise de escolhas binárias. 0 nome vem do fato de o modelo basear-se na função de probabilidade logística acumulada. Assumindo o modelo de regressão a seguir.

$$
y_{i}^{*}=\beta_{0}+\sum_{j=1}^{k} \beta_{i} x_{i j}+u_{i}
$$

em que $y_{i}^{*}$ é não observável, $y_{i}$ é uma variável binária (ou dummy) observável definida como:

$$
y_{i}=\left\{\begin{array}{l}
1, \quad \text { se } y_{i}^{*}>0 \\
0, \text { caso contrário }
\end{array}\right.
$$

A variável $y_{i}^{*}$ pode ser interpretada como a propensão $\left(P_{i}\right)$ de $y_{i}$ assumir o valor 1 (a probabilidade de o agente fazer determinada escolha): 


$$
\begin{aligned}
& P_{i}=p(y=1)=P\left(y_{i}^{*}>0\right)=P\left[u_{i}>-\left(\beta_{0}+\sum_{j=1}^{k} \beta_{i} x_{i j}\right)\right] \\
& =1-F\left[-\left(\beta_{0}+\sum_{j=1}^{k} \beta_{i} x_{i j}\right)\right] \\
& P_{i}=1-F(-Z), \text { tal que } Z=\beta_{0}+\sum_{j=1}^{k} \beta_{i} x_{i j}
\end{aligned}
$$

em que $\mathrm{F}$ é a função de distribuição cumulativa do termo de erro $u_{i}$. Admitindo-se que a distribuição de $u_{i}$ é simétrica:

$$
\begin{aligned}
& P_{i}=[1-F(-Z)]=F(Z) \\
& P_{i}=F\left(\beta_{0}+\sum_{j=1}^{k} \beta_{i} x_{i j}\right)
\end{aligned}
$$

os valores de $y_{i}$ são resultados de um processo binomial com probabilidades dadas pela equação 4 e variam de acordo com mudanças na variável $x_{i j}$. Para esse tipo de modelo, a técnica mais adequada de estimação é através da máxima verossimilhança, que pode ser escrita como:

$$
L=\prod_{y_{i}=1} P_{i} \prod_{y_{i}=0}\left(1-P_{i}\right)
$$

A equação que representa a função de distribuição logística acumulada é:

$$
P_{i}=\frac{e^{Z_{i}}}{1+e^{Z_{i}}}
$$

Da relação entre $P_{i}$ e $Z_{i}$ na equação, pode-se observar que $P_{i}$ está relacionado não linearmente a $Z$, (consequentemente $x_{i j}$ ) e $P_{i}$ varia entre 0 e 1 à medida que $Z_{i}$ varia de $-\infty$ a $+\infty$.

O complementar de $P_{i}$ (chance de que o evento não ocorra) pode ser descrito como:

$$
1-P_{i}=\frac{1}{1+e^{Z_{i}}}
$$

Dividindo-se $P_{i}$ por $\left(1-P_{i}\right)$ : 


$$
\frac{P_{i}}{1-P_{i}}=\frac{\frac{e^{Z_{i}}}{1+e^{Z_{i}}}}{\frac{1}{1+e^{Z_{i}}}}=e^{Z_{i}}
$$

$P_{i} /\left(1-P_{i}\right)$ é a razão de chances a favor de que um evento ocorra. Tomando-se o logaritmo da equação

$$
L_{i}=\ln \left(\frac{P_{i}}{1-P_{i}}\right)=\ln \left(\frac{F\left(Z_{i}\right)}{1-F\left(Z_{i}\right)}\right)=Z_{i}=\beta_{0}+\sum_{j=1}^{k} \beta_{i} x_{i j}
$$

se $L$, for positivo, significa que a chance de que um evento ocorra cresce quando o valor do regressor aumenta. Caso contrário, se $L$, for negativo, a de que um evento ocorra diminui à medida que o valor do regressor aumenta. O coeficiente angular $\beta_{i}$ mede a variação em $L$ para uma unidade de variação no seu respectivo regressor $x_{i j}$. Os coeficientes indicam quanto o logaritmo das chances favoráveis a que um evento ocorra varia em resposta à variação de uma unidade nos regressores (Gujarati, 2011). O intercepto $\beta_{0}$ é o valor do logaritmo das chances favoráveis a que um evento ocorra quando todos regressores $x_{i j}$ são iguais a zero.

Para verificar a confiabilidade do modelo, utilizou-se, além da análise da significância dos coeficientes, a medida conhecida como Pseudo $\mathrm{R}^{2}$ ou $\mathrm{R}^{2}$ de McFadden, já que a medida $\mathrm{R}^{2}$ convencional, comumente usada para avaliar a qualidade de modelos econométricos, mostra problemas em modelos cuja variável $y$ apresenta apenas dois valores.

$$
R^{2} \text { de McFadden }=1-\frac{\log L_{U R}}{\log L_{R}}
$$

em que $L_{U R}$ é o máximo da função de verossimilhança quando maximizada com respeito a todos os parâmetros, e $L_{R}$ é o máximo da função de verossimilhança quando maximizada dado que todos os $\beta_{i}$ são iguais a zero.

Outra medida de ajustamento utilizada será o $\mathrm{R}^{2}$ Contado, que é um $\mathrm{R}^{2}$ calculado em termos de proporção de previsões corretas. Sendo $y_{i}$ uma variável que assume os valores zero ou um e $\widehat{y}_{l}$ varia de zero a um, pode-se classificar $\widehat{y_{l}^{*}}$ como 1 se $\widehat{y}_{l}>0,5$ e $\widehat{y_{l}^{*}}$ como 0 , caso contrário. 


$$
\widehat{y_{l}^{*}}= \begin{cases}1, \text { se } \widehat{y}_{l} & \text { se }>0,5 \\ 0, \text { se } \widehat{y}_{l} & \text { se }<0,5\end{cases}
$$

A partir desse conceito é possível calcular o $R^{2}$ Contado como:

$$
R^{2} \text { Contado }=\frac{\text { número de previsões corretas }}{\text { número total de observações }}
$$

Embora não tenha poder discriminatório suficiente, essa medida serve como ótima alternativa de análise da capacidade de previsão do modelo.

\section{RESULTADOS E DISCUSSÕES}

O método foi aplicado a 98 alunos, entre eles 61 homens (62\%) e 37 mulheres (38\%), divididos em sete turmas de diferentes tamanhos: 22 (2015.2 noturno), 20 alunos (2013.1 diurno), 16 (2014.1 diurno), 12 (2013.2 diurno e 2015.2 diurno), dez (2015.1 diurno), oito (2014.2 diurno). Todos os alunos são oriundos da Faculdade de Economia, Administração, Atuárias e Contabilidade - FEAAC, curso de Ciências Econômicas, da Universidade Federal do Ceará. Os experimentos geraram no total 724 interações: 98 do tipo simultâneo, 528 repetido infinito e 98 repetido finito, resumidos na Tabela 3 e no Gráfico 1. 
Tabela 3: Decisões tomadas em todos os jogos

\begin{tabular}{l|l|l|l|l}
\hline TIPO DE JOGO & $\begin{array}{c}\text { QUANTIDADE } \\
\text { DE } \\
\text { PARTICIPANTES }\end{array}$ & $\begin{array}{c}\text { \% } \\
\text { COOPERA }\end{array}$ & $\begin{array}{c}\text { \% NÃO } \\
\text { COOPERA }\end{array}$ \\
\hline 1 & Simultâneo & 98 & 19,4 & 80,6 \\
\hline 2 & Repetitivo Infinito & 98 & 65,3 & 34,7 \\
\hline 3 & Repetitivo Infinito & 78 & 79,5 & 20,5 \\
\hline 4 & Repetitivo Infinito & 78 & 83,3 & 16,7 \\
\hline 5 & Repetitivo Infinito & 78 & 85,9 & 14,1 \\
\hline 6 & Repetitivo Infinito & 56 & 76,8 & 23,2 \\
\hline 7 & Repetitivo Infinito & 56 & 80,4 & 19,6 \\
\hline 8 & Repetitivo Infinito & 22 & 72,7 & 27,3 \\
\hline 9 & Repetitivo Infinito & 22 & 86,4 & 13,6 \\
\hline 10 & Repetitivo Infinito & 10 & 80,0 & 20,0 \\
\hline 11 & Repetitivo Infinito & 10 & 80,0 & 20,0 \\
\hline 12 & Repetitivo Infinito & 10 & 60,0 & 40,0 \\
\hline 13 & Repetitivo Infinito & 10 & 80,0 & 20,0 \\
\hline Final & Repetitivo finito & 98 & 73,5 & 26,5 \\
\hline
\end{tabular}

Fonte: Elaborada pelos autores

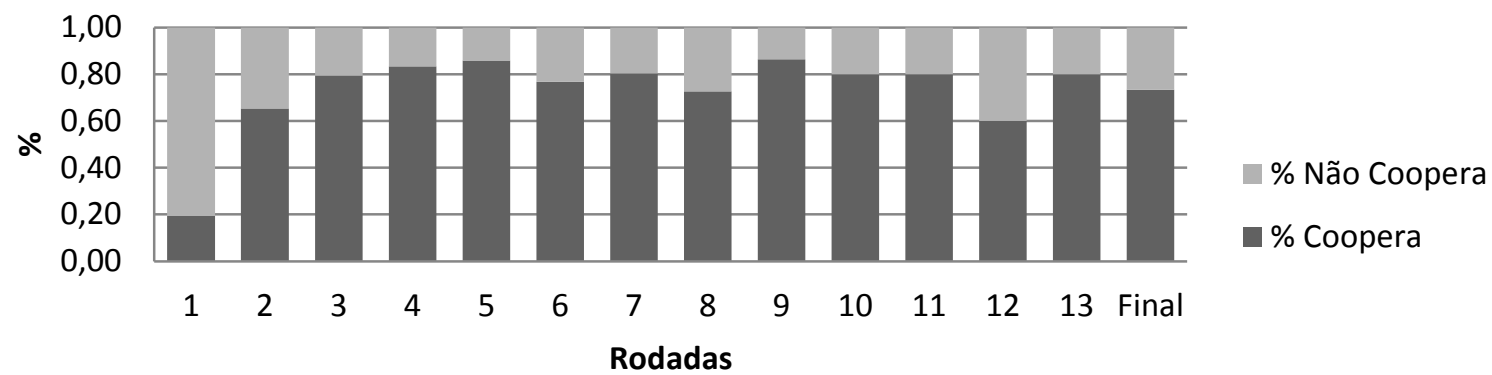

\section{Gráfico 1: Decisões tomadas em todos os jogos}

Fonte: Elaborado pelos autores

Os dados mostram que, quanto maior a quantidade de participantes no experimento, menos rodadas são executadas. Ou seja, partindo-se do pressuposto de que o tempo de computação das decisões seja igual, jogadores que participaram do experimento em turmas maiores, tentem a demorar mais tempo para decidir. Esse comportamento pode ser explicado pela seguinte hipótese: ao aumentar o número de participantes, a exposição ao julgamento dos colegas também aumenta já que as decisões individuais (erradas ou certeiras) são expostas a todos os participantes. Por sua vez, o conflito enfrentado ao decidir também aumenta e se reflete no tempo de decisão como demonstrado no Gráfico 2. 


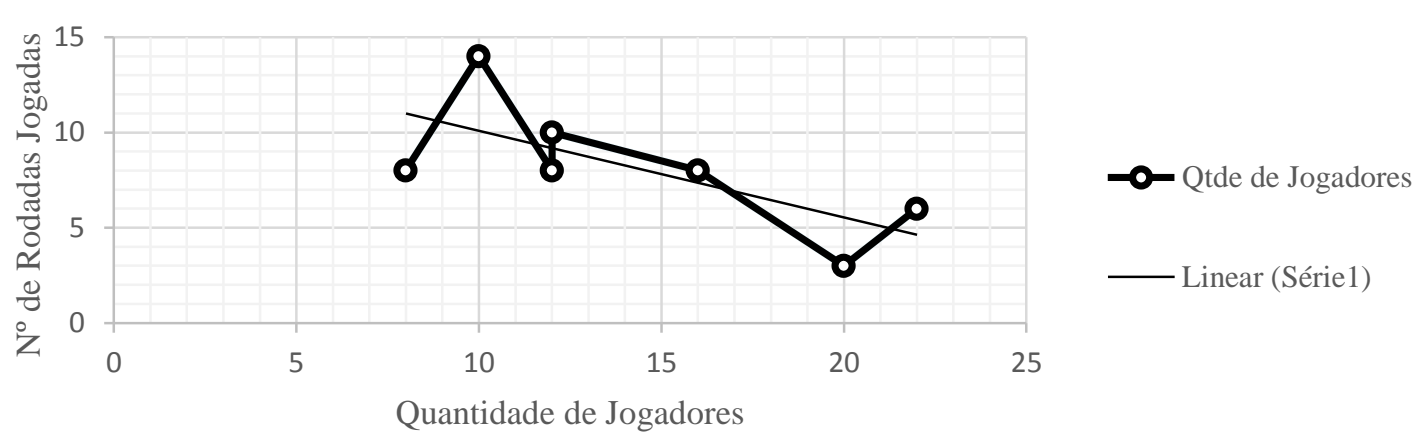

\section{Gráfico 2: Número de rodadas por quantidade de jogadores}

Fonte: Elaborado pelos autores

Quanto aos resultados, no jogo simultâneo, 80,6\% dos participantes agiram conforme a teoria e não cooperaram, contra 19,4\% que cooperaram. Os resultados evidenciam que os participantes que não cooperaram tiveram um ganho médio $163 \%$ maior que os demais.

Os dados revelam que nos jogos repetitivos infinitos, ou seja, sem prazo para conclusão, o comportamento cooperativo é preferido, assim como atesta a teoria, já que $77,8 \%$ dos resultados procederam da cooperação contra 22,2\% que não cooperaram. Os ganhos advindos da cooperação superaram em $2,8 \%$ os ganhos da não cooperação.

Os dados do jogo repetido finito deixam claro que a reputação entre os jogadores permite a cooperação mesmo sem garantias, já que $73 \%$ dos jogadores optaram pela cooperação. Entretanto, os prêmios advindos da não cooperação superam em torno de $25 \%$ os da cooperação, exatamente como descreve a teoria. Na Tabela 4, resumem-se tais resultados. 
Tabela 4: Resumo das decisões e seus respectivos resultados

\begin{tabular}{c|c|l|c|c|c}
\hline $\begin{array}{c}\text { TIPO DE } \\
\text { JOGO }\end{array}$ & $\begin{array}{c}\text { NÚMERO DE } \\
\text { RESULTADOS } \\
\text { ANALISADOS }\end{array}$ & \multicolumn{3}{|c|}{ DECISÃO TOMADA } & $\begin{array}{c}\text { GANHO } \\
\text { MÉDIO }\end{array}$ \\
\hline \multirow{2}{*}{ Simultâneo } & 98 & Cooperou & 19 & $19,4 \%$ & 1,63 \\
\cline { 3 - 5 } & & Não cooperou & 79 & $80,6 \%$ & 4,29 \\
\hline $\begin{array}{c}\text { Repetitivo } \\
\text { Infinito }\end{array}$ & \multirow{2}{*}{528} & Cooperou & 411 & $77,8 \%$ & 4,9 \\
\cline { 3 - 5 } $\begin{array}{c}\text { Repetitivo } \\
\text { Finito }\end{array}$ & \multirow{2}{*}{98} & Não cooperou & 117 & $22,2 \%$ & 4,5 \\
\cline { 3 - 5 } & & Nõoperou cooperou & 72 & $73,5 \%$ & 4,33 \\
\hline
\end{tabular}

Fonte: Elaborada pelos autores

\subsection{Resultado da estimação}

A partir das 724 observações retiradas dos experimentos, foi estimado modelo de tomada de decisão contendo seis variáveis descritas na Tabela 5. O modelo pode ser descrito como:

$Y=\operatorname{Pr}($ Coop $=1 /$ Gn, Coopaa, Gan, Qp, Expa,Ving $)$

A variável dependente $\mathbf{Y}$, que representa a probabilidade de 0 indivíduo cooperar, assume o valor de 1 se cooperar e 0 , caso contrário.

\section{Tabela 5: Variáveis utilizadas na estimação}

\begin{tabular}{l|l|l|l}
\hline ABREVIAÇÃO & VARIÁVEL & $\begin{array}{l}\text { VALOR DA } \\
\text { VARIÁVEL }\end{array}$ & OBJETIVO DA VARIÁVEL \\
\hline Gn & Gênero & $\begin{array}{l}\text { 1 se masculino } \\
\text { o se feminino }\end{array}$ & $\begin{array}{l}\text { Verificar se o gênero } \\
\text { influencia na cooperação }\end{array}$ \\
\hline Coopaa & $\begin{array}{l}\text { Cooperação anterior } \\
\text { adversária }\end{array}$ & $\begin{array}{l}\text { 1 se cooperou } \\
\text { 0 caso contrário }\end{array}$ & $\begin{array}{l}\text { Identificar e há o emprego } \\
\text { da estratégia tit-for-tat }\end{array}$ \\
\hline Gan & ganho & Variável quantitativa & $\begin{array}{l}\text { Avaliar a influência do valor } \\
\text { do ganho na cooperação }\end{array}$ \\
\hline Qp & $\begin{array}{l}\text { Quantidade de } \\
\text { pessoas }\end{array}$ & Variável quantitativa & $\begin{array}{l}\text { Aferir o conflito gerado pela } \\
\text { exposição ao julgamento } \\
\text { dos colegas }\end{array}$ \\
\hline Expa & Experiência anterior & $\begin{array}{l}\text { Número de rodadas } \\
\text { anteriores }\end{array}$ & $\begin{array}{l}\text { Medir o impacto da } \\
\text { experiência na cooperação }\end{array}$ \\
\hline Ving & $\begin{array}{l}\text { Possibilidade de } \\
\text { vingança }\end{array}$ & $\begin{array}{l}\text { Conferir se a possibilidade } \\
\text { de vingança é levada em } \\
\text { consideração na decisão }\end{array}$ \\
\hline
\end{tabular}

Fonte: Elaborada pelos autores

Na Tabela 6, são apresentados os resultados da estimação.

Tabela 6: Resultados da estimação 


\begin{tabular}{|c|c|c|c|c|c|}
\hline Iteration 0: & $\begin{array}{l}\text { Log } \\
\text { likelihood= }\end{array}$ & -446.25733 & & & \\
\hline Iteration 1: & $\begin{array}{l}\text { Log } \\
\text { likelihood= }\end{array}$ & -332.12362 & & & \\
\hline Iteration 2: & $\begin{array}{l}\text { Log } \\
\text { likelihood= }\end{array}$ & -327.46592 & & & \\
\hline Iteration 3: & $\begin{array}{l}\text { Log } \\
\text { likelihood= }\end{array}$ & -327.43414 & & & \\
\hline Iteration 4: & $\begin{array}{l}\text { Log } \\
\text { likelihood= }\end{array}$ & -327.43413 & & & \\
\hline \multirow[t]{3}{*}{$\begin{array}{l}\text { Logistic } \\
\text { regression }\end{array}$} & & $\begin{array}{l}\text { Number of } \\
\text { obs }\end{array}$ & 724 & & \\
\hline & & LR chi2(6) & 237.65 & & \\
\hline & & Prob $>$ chi2(6) & 0.0000 & & \\
\hline \multirow[t]{2}{*}{$\begin{array}{l}\text { Log } \\
\text { likelihood= }\end{array}$} & -327.43413 & Pseudo R2 & 0.2663 & & \\
\hline & & Count R2 & 0.776 & & \\
\hline Coop & Coef. & Std. Err. & $\mathbf{z}$ & $P>|z|$ & $\begin{array}{l}\text { [95\% Conf. } \\
\text { Interval] }\end{array}$ \\
\hline Gn & 0.2031 & 0.2014 & 1.01 & 0.313 & -0.1916217 \\
\hline Coopaa & 2.2789 & 0.2282 & 9.99 & 0.000 & 1.831770 \\
\hline Gan & -0.161 & 0.0457 & -3.52 & 0.000 & -0.2503920 \\
\hline Qp & 0.0488 & 0.022 & 2.22 & 0.026 & 0.0057230 \\
\hline Expa & 0.0484 & 0.0367 & 1.32 & 0.188 & -0.0236480 \\
\hline Ving & 1.2466 & 0.2168 & 5.75 & 0.000 & 0.8217369 \\
\hline Cons & -1.424 & 0.4798 & -2.97 & 0.003 & -2.3647180 \\
\hline
\end{tabular}

Fonte: Elaborada pelos autores

No total foram necessárias cinco interações para estimar o modelo. A estatística Prob Qui-quadrado indica que se pode rejeitar ao nível de $1 \%$ a hipótese de que todos os coeficientes sejam iguais a zero.

O $R^{2}$ de McFadden indica que $26,63 \%$ da variação da variável dependente pode ser explicada pelas variáveis independentes do modelo, enquanto $R^{2}$ Contado revela que de modo geral o modelo prevê $77,6 \%$ das observações corretamente.

As variáveis Coopaa e Gan mostraram-se estatisticamente significantes ao nível de $1 \%$ e a variável Qp ao nível de 5\%. Ainda nesse modelo, as variáveis Gn e Expa revelaram-se estatisticamente irrelevantes ao nível de $5 \%$.

\section{Tabela 7: 1Efeitos marginais das variáveis estatisticamente significantes}




\begin{tabular}{|c|c|c|c|c|c|c|c|}
\hline \multicolumn{8}{|c|}{$\begin{array}{l}y=\operatorname{Pr}(\text { coop }) \text { (predict) } \\
=.75329231\end{array}$} \\
\hline Variable & $d y / d x$ & Std.Err. & $z$ & $P>|z|$ & \multicolumn{2}{|c|}{$[95 \%$ C.I. $]$} & $\mathrm{X}$ \\
\hline Coopaa* & 0.444594 & 0.04003 & 11.11 & 0.000 & 0.366128 & 0.523061 & 0.595304 \\
\hline Gan & -0.02989 & 0.00855 & -3.50 & 0.000 & -0.04664 & -0.01314 & 4.57459 \\
\hline Qp & 0.009072 & 0.0041 & 2.22 & 0.027 & 0.001045 & 0.017098 & 14.232 \\
\hline Ving* & 0.258979 & 0.04798 & 5.40 & 0.000 & 0.164941 & 0.353018 & 0.729282 \\
\hline
\end{tabular}

Fonte: Elaborada pelos autores

Os resultados dos feitos marginais revelam que a probabilidade de haver cooperação no ponto médio é de $75,33 \%$ para a amostra utilizada. A cooperação anterior do adversário (Coopaa) aumenta em 44,46\% as chances de o indivíduo cooperar, confirmando o emprego da estratégia titfor-tat entre os jogadores.

O ganho tem impacto negativo na cooperação. O acréscimo de uma unidade na variável Gan diminui em 2,99\% as chances da cooperação. 0 fato sugere que a hipótese da racionalidade (indivíduo maximizador de bem-estar) é razoável para a amostra.

A variável quantidade de pessoas $\mathrm{Qp}$, influi positivamente na cooperação. O acréscimo de uma pessoa ao jogo aumenta em cerca de $1 \%$ as chances de cooperação. A exposição ao julgamento também pode servir de hipótese sobre o comportamento dessa variável. Como na maior parte da dinâmica o resultado cooperativo se apresenta mais vantajoso, o participante que não coopera pode ser mal visto pelos colegas já que suas decisões são expostas a todos os jogadores.

Para a amostra, a possibilidade de vingança, como na teoria, influencia positivamente o estabelecimento de acordo entre os concorrentes já que aumenta em $25,90 \%$ as chances da cooperação.

\section{CONCLUSÕES}

O uso das simulações aumentou consideravelmente o interesse dos alunos pelos estudos de jogos, e praticamente a totalidade dos estudantes que participaram do experimento desenvolveu algum comportamento descrito em teoria. O fato confirma que o aprendizado por tentativa e erro é uma maneira eficiente de aproximar a teoria da realidade, evidenciando as minúcias e as aplicabilidades do conhecimento em jogos. 
Foi observado que o processo de decisão é influenciado pelo conflito gerado pelo fator emocional, que se refletiu principalmente no tempo de decisão. $O$ fator social também se mostrou relevante na tomada de decisão já que a quantidade de participantes presentes no experimento influencia a escolha entre cooperar ou não. A hipótese é que a exposição ao julgamento cresce quando aumenta o número de participantes em cada dinâmica, o que faz com que o indivíduo demore mais tempo para fazer suas escolhas.

Nesta amostra específica, essa mesma exposição pode ter servido de impulso à cooperação. A possível explicação é que a expressiva maioria dos jogos analisados apresenta equilíbrio cooperativo, pois, caso o estudante resolva não cooperar, pode ser visto como mau jogador entre os colegas. Entretanto a hipótese da racionalidade apresentou razoável eficiência em prever decisões tomadas pelos participantes, já que, em $80 \%$ dos jogos simultâneos e em $77,8 \%$ dos jogos repetidos infinitamente, os jogadores agiram de modo economicamente racional e os que agiram de forma contrária obtiveram ganhos médios inferiores. No jogo repetitivo finito, $73 \%$ agiram de maneira contrária à racionalidade econômica, porém obtiveram resultado médio $33,2 \%$ menor que os demais.

Para a amostra analisada, as variáveis ganho, cooperação adversária anterior e possibilidade de vingança influenciam a tomada exatamente como descreve a teoria. Os resultados do modelo logit deixam claro que grande parte da amostra se comportou como previsto e as estratégias descritas na teoria foram as que geraram maior resultado. A teoria dos jogos mostrou-se robusta nas aplicações utilizadas ao conseguir descrever todos os desfechos e quais escolhas levam aos melhores resultados possíveis.

\section{REFERÊNCIAS}


Fiani, R. (2006). Teoria dos jogos: para cursos de administração e economia (2a ed.). Rio de Janeiro: Elsevier.

Grâmigna, M. R. M. (1993). Jogos de empresa. São Paulo: Makron Books.

Gujarati, D.N. (2011). Econometria básica (5a ed.). Porto Alegre: AMGH.

Rocha, A. F., \& Freitas, F. T. (2011). Neuroeconomia e processo decisório.

Rio de Janeiro: LTC. 


\section{ANEXO I - JOGO DOS POSTOS DE GASOLINA}

Em uma pequena cidade há apenas dois postos de gasolina (Posto $\mathrm{A}$ e Posto B), um bem próximo ao outro. Os dois postos estão considerando agir como cartel para determinar preços mais altos. Cada administrador no início do mês define o preço do litro da gasolina que deve permanecer por pelo menos um mês.

Se os dois postos oferecerem preços iguais e mais altos, os dois terão um lucro maior ( $\mathrm{R} \$ 5.000,00$ cada) e dividirão o mercado.

No entanto, se apenas um deles aumentar o preço e o outro não, o posto com o menor preço vai ganhar todo o mercado, e terá um lucro ainda maior do que se participasse do cartel $(R \$ 9.000,00)$.

Da mesma forma, o posto que elevar o preço sozinho teria um lucro menor que o lucro do cartel $(R \$ 1.000,00)$.

Se os dois postos não elevarem seus preços, eles continuam dividindo o mercado, mas com um lucro menor que o lucro do cartel ( $R \$$ $3.000,00$ cada).

Sabendo que os postos só funcionarão durante um mês, qual será sua decisão?

\section{Aumentar ou manter o preço no mês?}

\section{ANEXO II - JOGO DOS RESTAURANTES}

Em uma pequena cidade no litoral há apenas dois hotéis (hotel A e hotel B), um bem próximo ao outro. Os dois hotéis estão considerando agir como cartel para determinar preços mais altos. Cada administrador no início da alta estação define o preço da hospedagem que deve permanecer até o fim do período.

Se os dois hotéis oferecerem preços iguais e mais altos os dois dividirão o mercado e terão um lucro maior ( $R \$ 5.000,00$ cada).

No entanto, se apenas um deles aumentar o preço e o outro não, o hotel com o menor preço vai ganhar todo o mercado, e terá um lucro ainda maior do que se participasse do cartel $(R \$ 9.000,00)$. Desse modo, o hotel 
que elevar o preço sozinho terá um lucro menor que o lucro do cartel ( $R$ \$ $1.000,00)$ referente às reservas já realizadas.

Se os dois hotéis não elevarem seus preços, eles continuam dividindo o mercado, mas com um lucro menor que o lucro do cartel ( $R$ \$ $3.000,00$ cada).

\section{Sabendo que os hotéis só funcionarão durante uma} temporada de alta estação, qual será sua decisão?

\section{Aumentar ou manter o preço no mês?}

\section{ANEXO III - JOGO DAS MONTADORAS}

Em um pequeno país da Ásia há apenas duas montadoras de automóveis (montadora A e montadora B).

As duas têm atuação em todo o país e estão considerando agir como cartel para determinar preços mais altos.

O administrador de cada montadora define no início do ano o preço do carro, que deve permanecer por pelo menos um ano.

Se as duas montadoras oferecerem preços iguais e mais altos, as duas terão um lucro maior ( $€ 5$ milhões cada) e dividirão o mercado.

No entanto, se apenas uma delas aumentar o preço e a outra não, a montadora com o menor preço vai ganhar todo o mercado, e terá um lucro ainda maior do que se participasse do cartel ( $€ 9$ milhões).

Da mesma forma, a montadora que elevar o preço sozinha teria um lucro menor que o lucro do cartel ( $€ 1$ milhão).

Se as duas montadoras não elevarem seus preços, elas continuam dividindo o mercado, mas com um lucro menor que o lucro do cartel ( $€ 3$ milhões cada).

Sabendo que as montadoras só funcionarão durante um ano, o que você sugere? Aumentar ou manter o preço no mês? 